\title{
Six degrees head-down tilt bed rest caused low-grade hemolysis: a prospective randomized clinical trial
}

\author{
Kathryn Culliton ${ }^{1}$, Hakim Louati ${ }^{1}$, Odette Laneuville $\mathbb{D}^{2}$, Tim Ramsay ${ }^{3}$ and Guy Trudel ${ }^{1,4 凶}$
}

This study aimed to measure hemolysis before, during and after 60 days of the ground-based spaceflight analog bed rest and the effect of a nutritional intervention through a prospective randomized clinical trial. Twenty male participants were hospitalized for 88 days comprised of 14 days of ambulatory baseline, 60 days of $6^{\circ}$ head-down tilt bed rest and 14 days of reambulation. Ten participants each received a control diet or daily polyphenol associated with omega-3, vitamin $\mathrm{E}$, and selenium supplements. The primary outcome was endogenous carbon monoxide (CO) elimination measured by gas chromatography. Hemolysis was also measured with serial bilirubin, iron, transferrin saturation blood levels and serial 3-day stool collections were used to measure urobilinoid excretion using photometry. Total hemoglobin mass (tHb) was measured using CO-rebreathing. CO elimination increased after 5, 11, 30, and 57 days of bed rest: $+289 \mathrm{ppb}(95 \% \mathrm{Cl} 101-477 \mathrm{ppb}$; $p=0.004),+253 \mathrm{ppb}(78-427 \mathrm{ppb} ; p=0.007),+193 \mathrm{ppb}(89-298 \mathrm{ppb} ; p=0.001)$ and $+858 \mathrm{ppb}(670-1046 \mathrm{ppb} ; p<0.000)$, respectively, compared to baseline. Bilirubin increased after 20 and 49 days of bed rest $+0.8 \mathrm{mg} / \mathrm{l}(p=0.013)$ and $+1.1 \mathrm{mg} / \mathrm{l}$ $(p=0.012)$, respectively; and iron increased after 20 days of bed rest $+10.5 \mu \mathrm{g} / \mathrm{dl}(p=0.032)$. The nutritional intervention did not change CO elimination. THb was lower after 60 days of bed rest $-0.9 \mathrm{~g} / \mathrm{kg}(p=0.001)$. Bed rest enhanced hemolysis as measured through all three by-products of heme oxygenase. Ongoing enhanced hemolysis over 60 days contributed to a $10 \%$ decrease in $\mathrm{tHb}$ mass. Modulation of red blood cell control towards increased hemolysis may be an important mechanism causing anemia in astronauts.

npj Microgravity (2021)7:4; https://doi.org/10.1038/s41526-021-00132-0

\section{INTRODUCTION}

Space anemia after exposure to microgravity was first observed in six astronauts from Gemini missions ${ }^{1}$. Later studies correcting for environmental oxygen concentrations failed to resolve the anemia in 4 returning astronauts from the Spacelab 1 mission ${ }^{2}$. Further experiments identified a $10-15 \%$ decrease in erythrocyte mass measured in three astronauts after 9 days $^{3}$ and in six astronauts after 9 and 14 days in space ${ }^{4}$. More recently, longer-duration space missions followed erythropoietic adaptation to space after the initial 10 days and reported no anemia onboard the ISS throughout 6-month missions questioning whether space anemia was real or had been resolved with modern space travel ${ }^{5}$. However, epidemiological data from over 5 decades of American and Canadian presence in space confirmed and characterized space anemia 6 .

The search for mechanisms to explain space anemia has generated multiple hypotheses and experiments over the past decades such as: ineffective erythrocyte production and/or egress from the bone marrow ${ }^{3,7,8}$, low erythropoietin levels or sensitivity ${ }^{3,4}$, and production of abnormally-shaped erythrocytes ${ }^{9}$. In situations of hemoconcentration the excess erythrocytes can be sequestered in the spleen ${ }^{7}$, remain in circulation until timedetermined senescence ${ }^{3}$, or their lifespan can be shortened preferentially affecting young erythrocytes ${ }^{4}$ or equally affecting erythrocytes of all ages ${ }^{10}$.

Hemolysis regulates erythropoietic homeostasis ${ }^{11-13}$. Alfrey proposed that upregulated hemolysis explained the decrease in total hemoglobin mass $(\mathrm{tHb})$ using data obtained by labeling erythrocytes ${ }^{3,4}$. However, this evidence for hemolysis was indirect $^{14}$. Volunteers exposed to bed rest with $6^{\circ}$ head-down tilt (HDT) also displayed lower tHb upon reambulation ${ }^{15-17}$. Clinically, an abundance of data demonstrates an association between bed rest and anemia ${ }^{18-35}$. However, there has been debate over whether this might be caused by a reduction in erythropoiesis, an increase in hemolysis, or both. Our trial sought to answer that question. In parallel, the effectiveness of a nutritional intervention of food plants, vitamin E and omega-3 at preventing deconditioning induced by bed rest was investigated. Its effect on hemolysis is unknown and was assessed ${ }^{36-38}$.

Hemolysis can be quantified directly by measuring degradation products of hemoglobin. Senescent red blood cells (RBC) release hemoglobin molecules. Each of the four heme rings is enzymatically degraded by heme oxygenases $(\mathrm{HO})^{11}$ producing equimolar amounts of $\mathrm{CO}$, biliverdin and ferrous ion ${ }^{12,13}$. Hemoglobin heme is the largest source of endogenous CO (85\%), which allows attributing changes in $\mathrm{CO}$ elimination at the lungs to changes in the steady-state rate of hemolysis ${ }^{39,40}$. CO elimination is the difference between alveolar and ambient $\mathrm{CO}$ concentrations ([CO]) at a stable ventilation rate. Each molecule of biliverdin from heme degradation is conjugated in the liver to bilirubin, excreted in the intestine, converted to urobilinoids and eliminated in the feces ${ }^{41}$. Finally, serum iron levels and iron-related proteins can be measured in the serum.

Our objectives were to assess: (1) the effect of exposure to 60 days of bed rest HDT, and (2) the effect of a nutritional intervention on hemolysis in 20 volunteers using carbon monoxide (CO) elimination as the primary outcome; (3) To assess the effect of hemolysis on $\mathrm{tHb}$ mass. Our hypotheses

\footnotetext{
${ }^{1}$ Department of Medicine, Division of Physical Medicine and Rehabilitation, Ottawa Hospital Research Institute, Ottawa, ON, Canada. ${ }^{2}$ Department of Biology, Faculty of Science, University of Ottawa, Ottawa, ON, Canada. ${ }^{3}$ School of Epidemiology and Public Health, University of Ottawa, Ottawa, ON, Canada. ${ }^{4}$ Department of Biochemistry, Microbiology, and Immunology, University of Ottawa, Ottawa, ON, Canada. ${ }^{\circledR}$ email: gtrudel@toh.ca
} 


\section{CONSORT 2010 Flow Diagram}

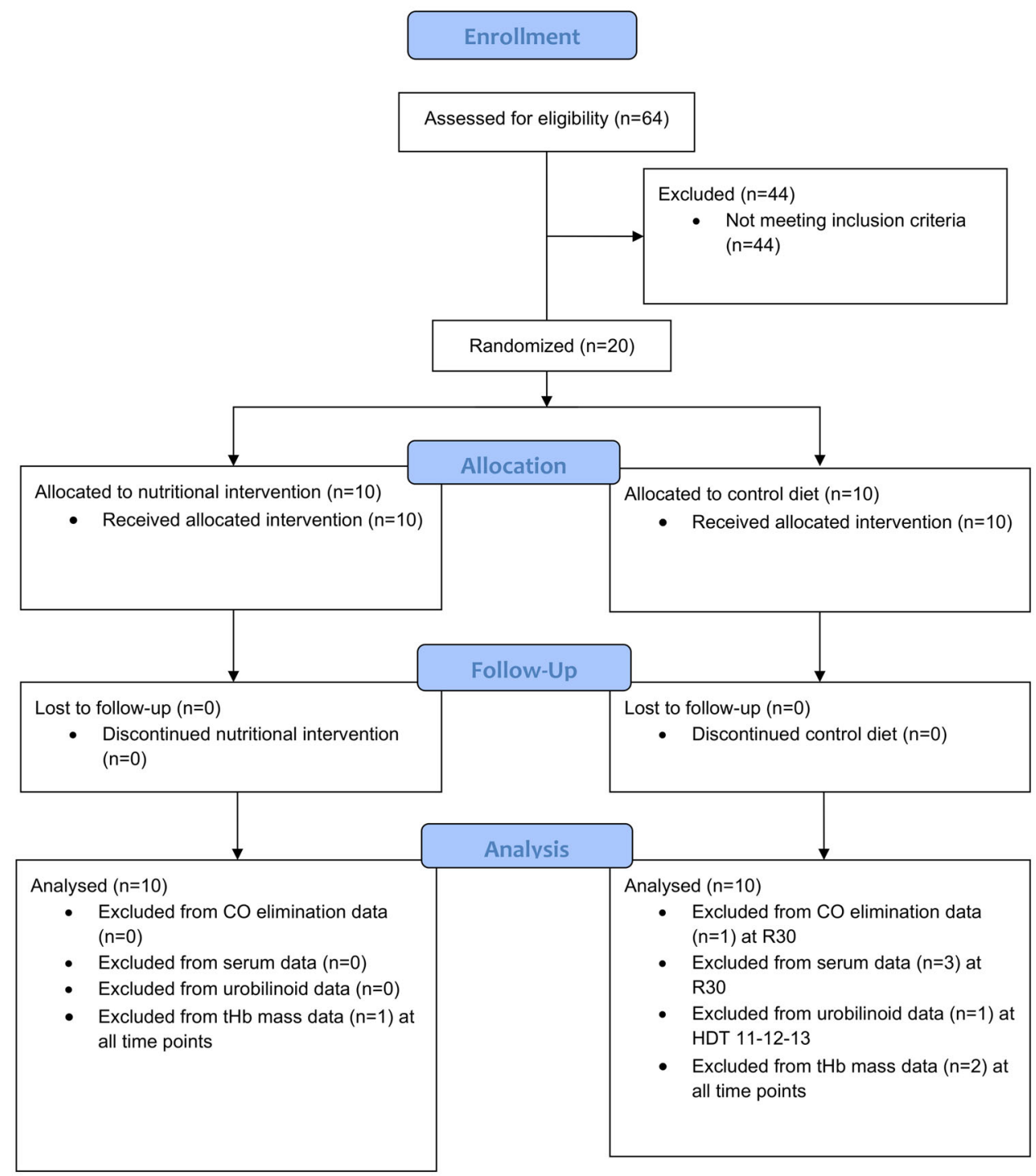

Fig. 1 CONSORT flow diagram for transparent reporting of trials. CO data from 1 participant at R30 was excluded due to admitted environmental factors (cigarette smoking). Blood was not drawn on three participants at reambulation Day 30 . Stool samples were not collected for one participant at HDT11,12,13. Total Hb mass determination was excluded for three participants due to technical difficulties.

were that: (1) exposure to bed rest HDT will increase hemolysis while (2) a nutritional intervention will have no effect; and (3) prolonged durations of increased hemolysis will contribute to anemia.

\section{RESULTS}

All participants (mean age 34.2 [SD, 7.8] years) completed the study (Fig. 1). There was no effect of the nutritional intervention on hemolysis (Supplementary Table 1 and Supplementary Fig. 1). Therefore, participants' data were combined $(n=20)$ to analyze the effect of exposure to bed rest on hemolysis.

\section{Hemolysis markers}

Baseline CO elimination was 1795ppb (95\% Cl: 1644-1947ppb; Table 2). CO elimination was higher after $5,11,30$, and 57 days of bed rest compared to baseline: $+289 \mathrm{ppb}$ (101-477 ppb), $+253 \mathrm{ppb}$ (78-427 ppb), +193 ppb (89-298 ppb) and $+858 \mathrm{ppb}$ (670-1046 ppb), respectively; (Fig. 2a). The average increase in CO elimination during bed rest was $23 \%$. CO elimination measured at reambulation days 5,12 , and 30 were comparable to baseline. Results from the two campaigns were comparable (Supplementary Fig. 2).

Iron was higher after 20 days of bed rest: $+10.5 \mu \mathrm{g} / \mathrm{dl}$ $(1.0-19.9 \mu \mathrm{g} / \mathrm{dl})$ compared to baseline (Fig. 2b). The average increase in serum iron during bed rest was $14 \%$. Iron was lower 

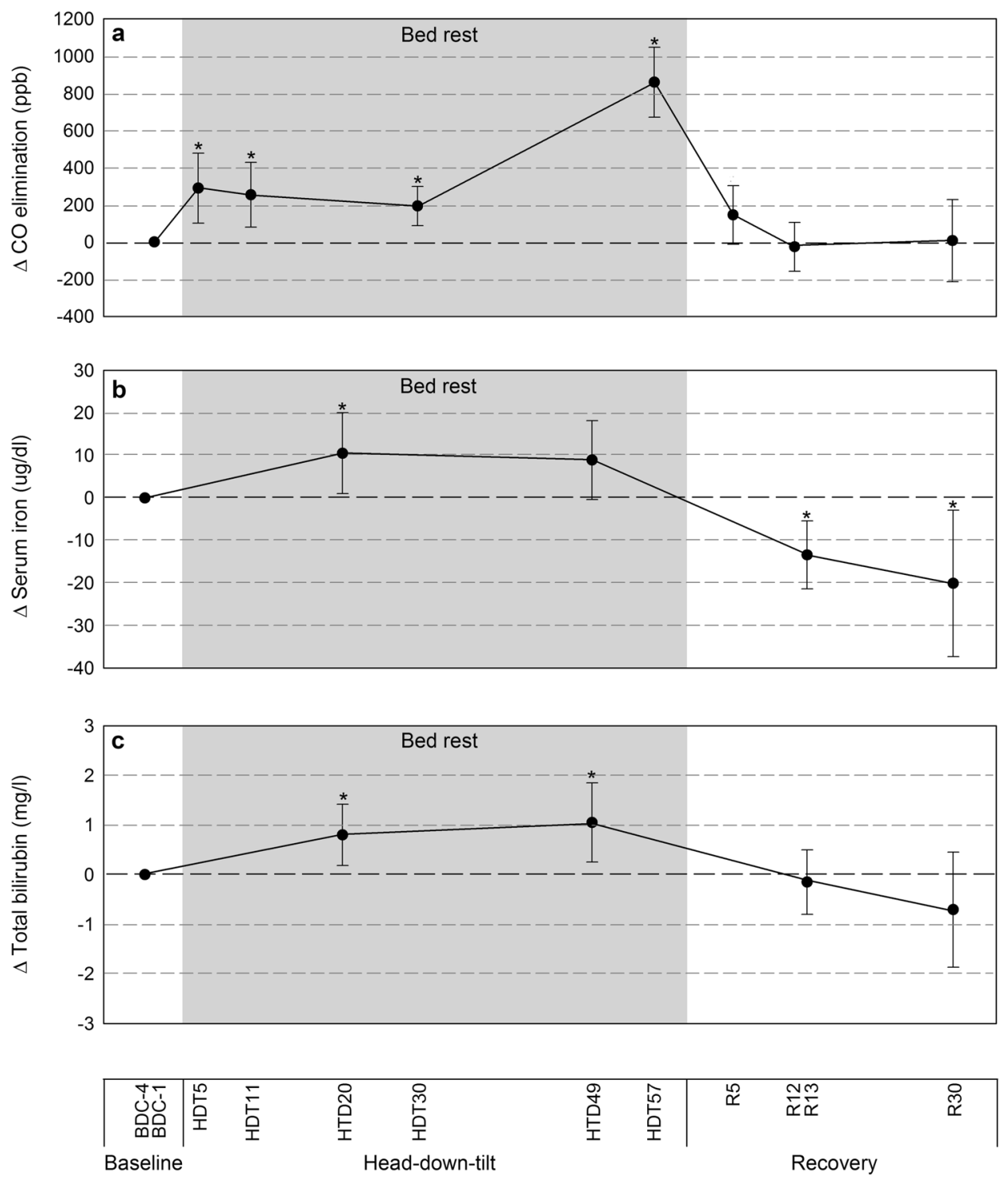

Fig. 2 Measures of the three by-products of heme degradation by the hemoglobin oxygenase enzymes in 20 male participants before, during and after $\mathbf{6 0}$ days of bed rest HDT. a Endogenous $\mathrm{CO}$ elimination was elevated at all time points during bed rest. $\mathbf{b}$ Iron levels were elevated after 20 days of bed rest and decreased below baseline after bed rest. c Bilirubin was elevated at all time points during bed rest. These findings support low-grade hemolysis with enforcing and maintaining the bed rest position. Data expressed as changes from baseline. Shaded area represents the bed rest HDT phase. BDC baseline data collection, HDT head-down tilt, R recovery or reambulation. Error bars: $95 \%$ confidence interval. ${ }^{*} p<0.05$ compared to baseline.

than baseline at reambulation days 13 and 30 (Fig. 2b and Table 1).

Total bilirubin was higher after 20 and 49 days of bed rest compared to baseline, $+0.8 \mathrm{mg} / \mathrm{l}(0.2-1.4 \mathrm{mg} / \mathrm{l})$ and $+1.1 \mathrm{mg} / \mathrm{l}$ (0.3-1.8 mg/l), respectively (Fig. $2 \mathrm{c}$ ). The average increase in total bilirubin during bed rest was $19 \%$.

Urobilinoids elimination was higher after 11-12-13, 30-31-32, and 56-57-58 days of bed rest: $+75.9 \mathrm{mg} /$ day $(-15.4-167.2 \mathrm{mg} /$ day), $+33.3 \mathrm{mg} /$ day $(-31.0-97.5 \mathrm{mg} /$ day $)$ and $+49.2 \mathrm{mg} /$ day (-29.6-128.0 mg/day), respectively (Table 1 ) but the confidence intervals included zero. The average increase in urobilinoids elimination during bed rest was $20 \%$.

The transferrin saturation was higher after 49 days of bed rest: $+4.1 \%(0.3-8.0 \%$; Table 1). The average increase in transferrin saturation during bed rest was $+15 \%$. Transferrin saturation was lower at reambulation days 13 and 30 . Haptoglobin was unchanged throughout bed rest (Table 2).

\section{Erythropoietic markers}

Red blood cell concentration was higher after 20,49, and 60 days of bed rest: $+48.210^{4} / \mathrm{mm}^{3}\left(3.8-5.810^{4} / \mathrm{mm}^{3}\right) ;+47.810^{4} / \mathrm{mm}^{3}$ (3.5-6.1 $\left.10^{4} / \mathrm{mm}^{3}\right)$, and $+27.410^{4} / \mathrm{mm}^{3}\left(1.6-3.910^{4} / \mathrm{mm}^{3}\right)$, respectively, compared to baseline (Fig. 3a). The average increase in red blood cell concentration during bed rest was $9 \%$. Red blood cell concentration was lower at reambulation day 13 (Fig. 3a and Table 2). Mean hemoglobin concentrations were $-0.55 \mathrm{~g} / \mathrm{dl}(-0.9$ to $-0.2 \mathrm{~g} / \mathrm{dl})$ and $-0.46 \mathrm{~g} / \mathrm{dl}(-0.9$ to $-0.1 \mathrm{~g} / \mathrm{dl})$ at reambulation days 13 and 30 , respectively (Table 2 ).

EPO was lower after 20 and 49 days of bed rest: $-3.3 \mathrm{mUl} / \mathrm{ml}$ $(-4.7$ to $-2.0 \mathrm{mUl} / \mathrm{ml})$, and $-2.1 \mathrm{mUI} / \mathrm{ml}(-3.4$ to $-0.7 \mathrm{mUI} / \mathrm{ml})$; respectively, compared to baseline (Fig. $3 \mathrm{~b}$ ). The average decrease in EPO during bed rest was $18 \%$. EPO was higher than baseline at reambulation days 13 and 30 .

Total hemoglobin mass was significantly lower after 60 days of bed rest and at reambulation day $7:-0.9 \mathrm{~g} / \mathrm{kg}(-1.4$ to $-0.4 \mathrm{~g} / \mathrm{kg})$ 

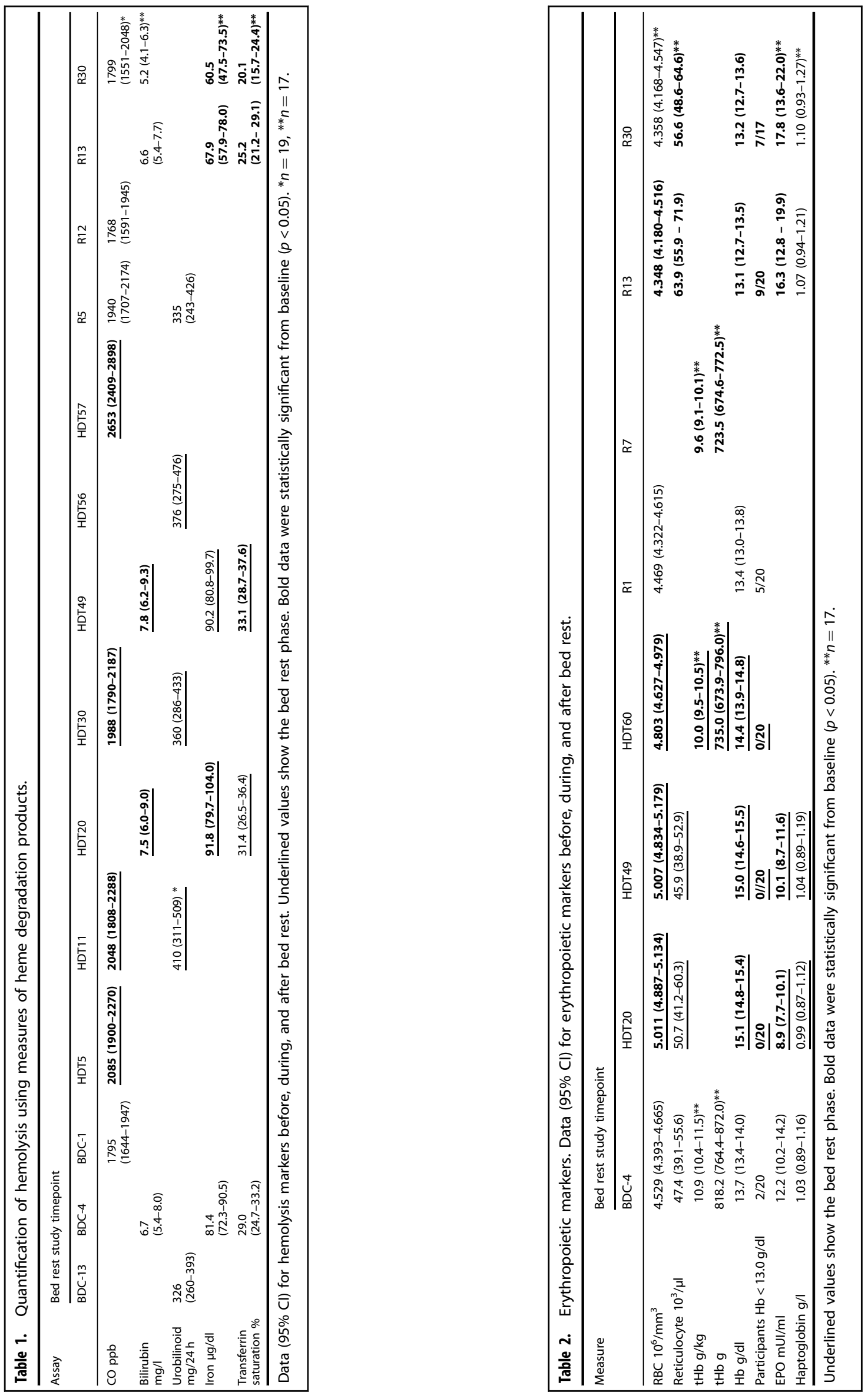

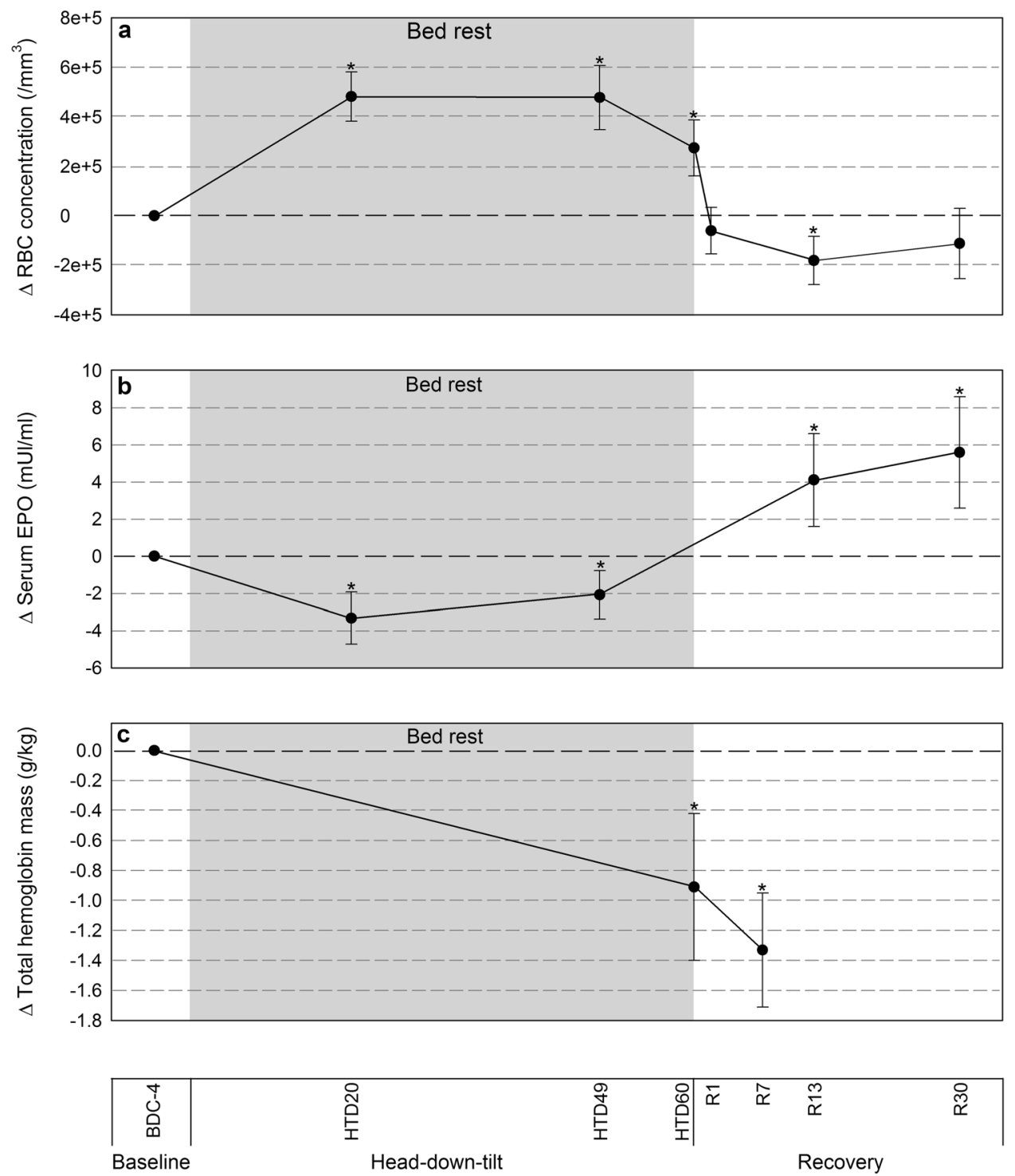

Fig. 3 Erythropoietic changes in 20 male participants before, during and after 60 days of bed rest HDT. a Participants remained hemoconcentrated at all time points during bed rest. Reambulation uncovered lower RBC concentration. $\mathbf{b}$ EPO was decreased at all time points during bed rest. EPO increased at reambulation. c Total hemoglobin mass was decreased after 60 days of bed rest and at recovery Day 7. Sixty days of bed rest caused a $77.2 \mathrm{~g}$ loss in tHb mass attributed to hemolysis and blood draws. Data expressed as changes from baseline. Shaded area represents the bed rest HDT phase. BDC: Baseline Data Collection; HDT: Head-Down Tilt; R: Recovery or Reambulation. Error bars: $95 \%$ Confidence Interval. ${ }^{*} p<0.05$ compared to baseline.

and $-1.3 \mathrm{~g} / \mathrm{kg}(-1.7$ to $-1.0 \mathrm{~g} / \mathrm{kg})$, respectively, compared to baseline (Fig. 3c). The average decrease in tHb mass between baseline and 60 days of bed rest was $10 \%$ (Table 2 ).

Reticulocyte concentrations were unchanged during bed rest (Table 2) but were higher than baseline at reambulation days 13 and $30:+16.610^{3} / \mu \mathrm{l}\left(0.9-2.410^{3} / \mu \mathrm{l}\right)$ and $+10.810^{3} / \mu \mathrm{l}(0.3-1.9$ $\left.10^{3} / \mu \mathrm{l}\right)$, respectively.

\section{DISCUSSION}

This prospective randomized clinical trial provided the first direct confirmation of enhanced hemolysis using the bed rest space analog model. In healthy men, $\mathrm{CO}$ elimination increased on average $23 \%$. The other heme degradation products were also elevated throughout bed rest (bilirubin $+19 \%$, urobilinoids $+20 \%$, iron $+14 \%$ and transferrin saturation $+15 \%)$. The difference in percent increase between the 3 by-products of heme oxygenase may be explained by their individual metabolic pathways. Bilirubin clearance accrues when production increases, ${ }^{42}$ in addition, the buffering of iron by various proteins ${ }^{43}$ may also decrease their levels. CO is not further degraded and constitutes a reliable marker of hemolysis ${ }^{44}$. Participants' enhanced hemolysis was synchronous with the bed rest position. All hemolysis markers increased from the first measures, remained elevated throughout the 60 days of bed rest, and returned to or below baseline levels at reambulation. Taken together, the increased levels of the three heme by-products in synchrony with bed rest confirmed our first hypothesis that exposure to bed rest HDT (head-down-tilt) increases hemolysis. The nutritional intervention designed to prevent deconditioning showed no effect on hemolysis, which confirmed the second hypothesis.

Sustained increased hemolysis can contribute to anemia. The participants in the current study experienced a mean $10 \%$ decrease in $\mathrm{tHb}$ mass at day 60 of bed rest. In fact, the hemoglobin concentration of $9 / 20$ participant reached clinical anemia levels ${ }^{45}$ at day 13 of reambulation (Table 2) confirming our 
third hypothesis. Increased hemolysis during bed rest in the HDT position may be related to low EPO, bone marrow unloading and circadian cycle.

Increased hemolysis was associated with an $18 \%$ decrease in EPO levels throughout bed rest. Low EPO levels have also been consistently reported with space missions ${ }^{46}$. They were interpreted as a response to hemoconcentration that triggered peripheral hemolysis of young $\mathrm{RBC}$ to rapidly return $\mathrm{RBC}$ concentration to normal levels ${ }^{4,10,46-48}$. In this trial, participants remained hemoconcentrated $(+9 \%)$, however, the unchanged reticulocyte concentration argued against their preferential hemolysis. Also, low EPO, hemoconcentration, and increased hemolysis persisted for 60 days and were not a rapid adaptation to the initial days of bed rest. Persistently low EPO levels with bed rest may participate directly or indirectly to hemolysis in the bone marrow. Erythroid progenitors and early erythroblasts are continuously generated in large excesses and the fraction surviving to complete differentiation is regulated by EPO levels ${ }^{49}$. Haptoglobin binds to free plasma hemoglobin; the unchanged haptoglobin levels in this study supported a predominantly extravascular mechanism of hemolysis ${ }^{50-52}$. Importantly, while low-grade hemolysis physiologically attenuated hemoconcentration, it was an inappropriate response to a low tHb mass (Fig. $3 \mathrm{c}$ ), which can contribute to anemia.

Bed rest unloads the skeleton and, therefore, the hemopoietic bone marrow. Mechanosensitive osteolineage cells directly interact with hemopoietic stem cells around bone marrow sinusoids ${ }^{53-55}$. While exercise stimulates erythropoiesis, the elimination of axial loading imposed by bed rest may inhibit RBC production ${ }^{56,57}$. Skeletal offloading can also impair hematopoiesis via the bone marrow adipose tissue (MAT) ${ }^{54,55}$. Inactivity increases MAT, which can impair hematopoiesis by occupying space and/or through paracrine action ${ }^{58}$. Tight reciprocal relationship between MAT and hematopoiesis ${ }^{59,60}$ support that adipocytes are negative regulators of hematopoietic stem cell ${ }^{55}$. Low EPO has also been shown to favor adipogenesis ${ }^{61}$. Each marrow adipocyte in the mouse displaced $\sim 30$ hematopoietic cells ${ }^{59}$ and could interact with more than 100 through direct contact or via reticular macrophages of the erythroblast islands ${ }^{62}$. Increased MAT can impede the migration of maturing erythroid cells from the erythroblast islands to the sinusoids for egress into circulation ${ }^{63}$ and increase hemolysis locally in the bone marrow. Fluid shift to the bone marrow may, similar to MAT increase ineffective erythropoiesis.

Enforced bed rest disrupts the activity cycle between daytime and nighttime. Aborting circadian oscillations may alter erythrocyte control since both heme synthesis and degradation molecules are central actors in multiple internal clocks and metabolic pathways ${ }^{64,65}$. Heme binding to CLOCK protein regulates circadian control ${ }^{66}$. Both heme biosynthesis enzyme delta-aminolevulinate synthase 1 and hemolysis enzymes $\mathrm{HO}$ in liver followed a circadian expression ${ }^{67-69}$. Expression of HO mRNA in the retina peaked in the morning and middle of the night ${ }^{11}$. Klemz showed that rhythmic heme degradation was required for normal circadian rhythms, possibly through $\mathrm{CO}$ signaling ${ }^{70}$. Bed rest abolished the oscillatory verticalization for 60 days and may have shifted the circadian cycle-dependent erythropoiesis-hemolysis balance towards increased hemolysis.

At reambulation, hemolysis levels readily returned to baseline; and reversed fluid shift resulted in decreased RBC concentration (Figs 2 and 3). This was accompanied by a strong erythropoietic response with increased EPO levels and reticulocyte concentrations to palliate the low RBC concentration and tHb mass. Both iron and transferrin saturation dropped below normal levels possibly reflecting iron mobilization for intense erythropoiesis and iron losses from blood draws.

Since bed rest HDT is a microgravity analog, persistently increased hemolysis supports continued astronaut monitoring throughout space missions since space anemia worsens with increasing duration of exposure to microgravity ${ }^{6}$.

Beyond applications to space medicine, these results may apply on Earth to patients with reduced mobility ${ }^{24}$ and the elderly ${ }^{27,28}$. These populations spend increased time in bed or in wheelchairs and suffer high prevalence of chronic anemia of unexplained etiology ${ }^{25-29,71-74}$. Our findings of low-grade hemolysis in healthy volunteers with enforced reduced mobility is novel but the study did not include a horizontal bed rest group. However, Mitlyng et al. had identified a similar 25\% shorter RBC lifespan in patients with arthritis limiting mobility and with chronic anemia ${ }^{75}$. Therefore, low-grade hemolysis may be the mechanism explaining the high prevalence of anemia in patients who remain bedridden for prolonged durations ${ }^{76-80}$. In these patients, different approaches may be needed to address increased hemolysis with bed rest. Should MAT accumulation be a major contributor, antagonists of the peroxisome proliferator-activated receptor- $\gamma$ may be favored $^{81}$. Should skeleton unloading or circadian dysregulation be culprits, minimizing time in bed with early mobilization and promoting physical activity may be beneficial. Finally, serum adenosine levels were found to be enhanced with hemolysis and in a hypoxic bedridden environment, and adenosine can modulate important metabolic processes as well as the immune response ${ }^{82}$.

There are several limitations associated with the presented work. Parallel investigations during this bed rest study required venipunctures of $483 \mathrm{ml}$ between baseline and day 60 of bed rest (Supplementary Fig. 3). Despite iron losses arising from the venipunctures, increased iron/transferrin saturation during bed rest indicated its enhanced release. Similarly, venipunctures participated in lowering the $\mathrm{tHb}$ mass, which could have lowered CO elimination proportionately. Again, a $23 \%$ increase in CO elimination was measured from a $10 \%$ smaller pool of RBCs further supporting enhanced hemolysis during bed rest. Concomitant investigations required biopsies of muscle and fat at baseline and bed rest Day 56. Myoglobin and cytochrome degradation may have increased $\mathrm{CO}$ elimination. $\mathrm{CO}$ at baseline appeared unaffected but biopsies may have contributed to the Day 57 CO elimination data (Fig. 2 and Supplementary Fig. 4). Owing to the small sample size and targeted physiological outcomes, we did not correct for multiple hypothesis-testing. Since all of baseline measures but one were carried out between BDC- 4 and BDC- 1 , they corresponded to the status within 4 days of the bed rest phase.

The ground-based spaceflight analog head-down tilt bed rest triggered enhanced hemolysis measured with all three byproducts of heme degradation. Persistent hemolysis over 60 days contributed to lower $\mathrm{tHb}$ mass. These results suggest that enhanced hemolysis may constitute one important mechanism linking anemia with microgravity in astronauts and anemia with bed rest on Earth.

\section{METHODS}

\section{Subjects and setting}

The study was sponsored by the Center National d'Etudes Spatiales and collaborator the European Space Agency. The study was approved by the Comité de protection des personnes Sud-ouest et outre-mer (ID-RCB:2016A00401-50), the Ottawa Health Science Network REB (20160925-01H) and registered at ClinicalTrials.gov: NCT03594799 (Date submitted: November 24 2017; Date posted: July 20 2018). Informed consent was obtained from all individual participants included in the study and all participants signed informed consent regarding publication of their data. The study ran at the MEDES space clinic in France between January 2017 and January 2018. A volunteer sample of 20 men were recruited via the clinic website and the media. Inclusion criteria included age (20 to 45years) and BMI (22 to $27 \mathrm{~kg} /$ $\mathrm{m}^{2}$ ). Exclusions included hematological diseases, recent blood donation, smokers and active medical treatment (Supplementary Detail 1). The sample size was selected to detect a change in fasting plasma triglycerides 
concentration with the nutritional intervention. Sixteen research groups carried out various investigations in parallel, which constrained the sampling schedule and explained the variable sampling times between outcome measures.

\section{Design, exposure, and intervention}

This prospective randomized clinical trial tested a nutritional intervention to prevent deconditioning from exposure to bed rest head-down tilt (HDT). The design included 2 identical campaigns of 10 volunteers starting 8 months apart. Each campaign was comprised of 14 days of baseline data collection (BDC), followed by 60 days of bed rest HDT, 14 days of recovery or reambulation (R), with follow-up at R30. The nutritional intervention consisted of half the participants receiving daily $741 \mathrm{mg}$ polyphenols, $2.1 \mathrm{~g}$ Omega-3, $168 \mathrm{mg}$ vitamin E and $80 \mu \mathrm{g}$ selenium (detailed nutritional intervention in Supplementary Detail 2).

\section{Quantification of hemolysis}

We quantified the three by-products of hemoglobin degradation by heme oxygenase. Alveolar and ambient air samples to measure CO concentrations ([CO]) were collected at eight time points, one during baseline data collection (BDC-1), four during bed rest (HDT5, HDT11, HDT30, HDT57), and three during reambulation (R5, R12, R30) (Supplementary Fig. 5). A ninth measure at BDC-14 was dropped due to equipment failure at study outset (Supplementary Fig. 6). CO elimination was performed according to Shahin ${ }^{83}$, which involves replication of the measures, and implemented major improvements over prior methods ${ }^{15}$. Briefly, alveolar and ambient air samples were collected upon waking at 07:00 hours. Alveolar air collection followed $20 \mathrm{~s}$ of breath holding. On expiration, the initial $400 \mathrm{ml}$ from large airways was discarded using a pressure-sensitive one-way valve, the remainder flowed to a $750 \mathrm{ml}$ collection bag. Ambient samples from the participants' rooms were collected simultaneously into separate $750 \mathrm{ml}$ bags. Air samples were analyzed using a gas chromatograph with a reduction gas detector at a precision of $5 \mathrm{ppb}$ (PeakPerformer1RCP, Peak Laboratories, CA $)^{84}$.

Each molecule of biliverdin from heme degradation is conjugated in the liver to bilirubin, excreted in the intestine, converted to urobilinoids and eliminated in the feces ${ }^{41}$. We collected stools over 3-day periods before bed rest (BDC-13,-12,-11), four times during bed rest (HDT11,12,13, HDT30,31,32, HDT56,57,58) and at reambulation (R5,6,7). Stools were protected from light and immediately frozen at $-20^{\circ} \mathrm{C}$. Later, each sample was thawed, weighed, homogenized and a $350 \mathrm{mg}$ aliquot was suspended with $16 \mathrm{mM} \mathrm{NaCl}$. Urobilinoids were extracted from $0.4 \mathrm{ml}$ of the suspension according to Kotal ${ }^{41}$. Briefly, the suspension was oxidized by Lugol iodine. Adding $54 \mathrm{mM}$ zinc acetate in dimethyl sulfoxide formed a zinc complex and $82 \mathrm{mM}$ of cysteine was added. The extraction process was repeated twice. The absorption of the zinc complex of oxidized urobilinoids at $508 \mathrm{~nm}$ was compared to a standard curve using photometry (Infinite200PRO, Tecan, Switzerland).

Total hemoglobin mass was measured using CO-rebreathing at baseline (BDC-4), at the end of bed rest (HDT60) and at reambulation (R7) according to Burge ${ }^{85}$. Briefly, participants breathed pure oxygen for $5 \mathrm{~min}$ before a baseline measure of carboxyhemoglobin. The participants then received an individualized dose of $\mathrm{CO}(50-90 \mathrm{ml})$ rebreathed for $10 \mathrm{~min}$ before a second measure of carboxyhemoglobin. $\mathrm{THb}$ was calculated using carboxyhemoglobin kinetics. Importantly, since exogenous CO washout requires $2-6 h^{86-89}$, we measured CO elimination at least 3 days after each $\mathrm{tHb}$ measures (Supplementary Fig. 4).

Blood samples were collected at $07 \mathrm{~h} 30 \mathrm{~min}$ at BDC-4, HDT20, HDT49, $\mathrm{R} 13$, and R30 and processed at Laboratoire Biopole, France (Accreditation 31.3.31158.1) for total bilirubin, serum iron, saturation of transferrin, EPO, and haptoglobin. $\mathrm{RBC}, \mathrm{Hb}$, and reticulocyte concentrations were sampled at the same time points plus at HDT60 and R1 (Supplementary Fig. 5). Since all baseline measures but one were carried between BDC-4 and BDC-1, they corresponded to the status within 4 days of the bed rest phase. The one measure outside that range was the 3-day stool collection of urobilinoids (from BDC-13 to BDC-11). All measures were performed blindly except for CO where the type of sample (ambient or alveolar) was disclosed in order to calibrate accordingly.

\section{Statistical methods}

There were 16 investigator groups each with primary and secondary outcomes. For our experiment, $\mathrm{CO}$ elimination constituted the primary outcome. The effect of nutritional intervention was assessed using Mann
Whitney U-tests. For the primary outcome measure (CO elimination) and all outcomes, data with $95 \%$ confidence interval are presented in Tables 1 and 2. For the primary outcome measure (CO elimination) and all outcomes, change from baseline with $95 \%$ confidence interval are presented in Results, and Figs 2 and 3. Paired $t$-test were ran between baseline and experimental time points with no correction for multiple testing.

\section{Reporting summary}

Further information on research design is available in the Nature Research Reporting Summary linked to this article.

\section{DATA AVAILABILITY}

Data will be made available upon reasonable request to the corresponding author.

Received: 12 September 2020; Accepted: 13 January 2021; Published online: 15 February 2021

\section{REFERENCES}

1. Fischer, C. L., Johnson, P. C. \& Berry, C. A. Red blood cell mass and plasma volume changes in manned space flight. JAMA 200, 579-583 (1967).

2. Leach, C. \& Johnson, P. Influence of spaceflight on erythrokinetics in man. Science 225, 216-218 (1984).

3. Udden, M. M., Driscoll, T. B., Pickett, M. H., Leach-Huntoon, C. S. \& Alfrey, C. P. Decreased production of red blood cells in human subjects exposed to microgravity. J. Lab. Clin. Med. 125, 442-449 (1995).

4. Alfrey, C. P., Udden, M. M., Leach-Huntoon, C., Driscoll, T. \& Pickett, M. H. Control of red blood cell mass in spaceflight. J. Appl. Physiol. 81, 98-104 (1996).

5. Kunz, H. et al. Alterations in hematologic indices during long-duration spaceflight. BMC Hematol. 17, 1-8 (2017).

6. Trudel, G., Shafer, J., Laneuville, O. \& Ramsay, T. Characterizing the effect of exposure to microgravity on anemia: more space is worse. Am. J. Hematol. 95, 267-273 (2020).

7. Tavassoli, M. Anemia of spaceflight. Blood 60, 1059-1067 (1982).

8. Blaber, E. A. et al. Microgravity reduces the differentiation and regenerative potential of embryonic stem cells. Stem Cells Dev. 24, 2605-2621 (2015).

9. Ivanova, S. M. et al. Physical-chemical properties of plasma membrane and function of erythrocytes of cosmonauts after long-term space flight. Acta Astronaut. 68, 1517-1522 (2011).

10. Risso, A., Ciana, A., Achilli, C., Antonutto, G. \& Minetti, G. Neocytolysis: none, one or many? A reappraisal and future perspectives. Front. Physiol. 5, 54 (2014).

11. Damulewicz, M., Loboda, A., Jozkowicz, A., Dulak, J. \& Pyza, E. Interactions between the circadian clock and heme oxygenase in the retina of Drosophila melanogaster. Mol. Neurobiol. 54, 4953-4962 (2017).

12. Landaw, S. A., Callahan, E. W. \& Schmid, R. Catabolism of heme in vivo: comparison of the simultaneous production of bilirubin and carbon monoxide. J. Clin. Invest. 49, 914-925 (1970).

13. Karabulut, B. \& Arcagok, B. C. A neglected and promising predictor of severe hyperbilirubinemia due to hemolysis: carboxyhemoglobin. Fetal Pediatr. Pathol. 39, 124-131 (2020).

14. Franco, R. S. The measurement and importance of red cell survival. Am. J. Hematol. 84, 109-114 (2009).

15. Trudel, G., Uhthoff, H. K. \& Laneuville, O. Hemolysis during and after 21 days of head-down-tilt bed rest. Physiol. Rep. 5, e13469 (2017).

16. Dunn, C. D. R., Lange, R. D., Kimzey, S. L., Johnson, P. C. \& Leach, C. S. Serum erythropoietin titers during prolonged bedrest; relevance to the anaemia of space flight. Eur. J. Appl. Physiol. Occup. Physiol. 52, 178-182 (1984).

17. Lampe, L. et al. Effects of simulated microgravity (HDT) on blood fluidity. J. Appl. Physiol. 73, 1366-1369 (1992).

18. Parry, S. M. \& Puthucheary, Z. A. The impact of extended bed rest on the musculoskeletal system in the critical care environment. Extrem. Physiol. Med. 4, 1-8 (2015).

19. Chant, C., Wilson, G. \& Friedrich, J. O. Anemia, transfusion, and phlebotomy practices in critically ill patients with prolonged ICU length of stay: a cohort study. Crit. Care 10, R140 (2006).

20. Rodriguez, R. M. et al. Nutritional deficiencies and blunted erythropoietin response as causes of the anemia of critical illness. J. Crit. Care 16, 36-41 (2001).

21. Napolitano, L. M. Anemia and red blood cell transfusion. Crit. Care Clin. 33, 345-364 (2017).

22. Docherty, A. B., Turgeon, A. F. \& Walsh, T. S. Best practice in critical care: anaemia in acute and critical illness. Transfus. Med. 28, 181-189 (2018). 
23. Thomas, J., Jensen, L., Nahirniak, S. \& Gibney, R. T. N. Anemia and blood transfusion practices in the critically ill: a prospective cohort review. Hear. Lung 39, 217-225 (2010).

24. Leal-Noval, S. R. et al. Effects of red blood cell transfusion on long-term disability of patients with traumatic brain injury. Neurocrit. Care 24, 371-380 (2016).

25. Perkash, A. \& Brown, M. Anemia in patients with traumatic spinal cord injury. J. Am. Paraplegia Soc. 9, 10-15 (1986).

26. Milionis, $\mathrm{H}$. et al. Anemia on admission predicts short- and long-term outcomes in patients with acute ischemic stroke. Int. J. Stroke 10, 224-230 (2015).

27. Guralnik, J. M., Eisenstaedt, R. S., Ferrucci, L., Klein, H. G. \& Woodman, R. C. Prevalence of anemia in persons 65 years and older in the United States: evidence for a high rate of unexplained anemia. Blood 104, 2263-2268 (2004).

28. Patel, K. V. Epidemiology of anemia in older adults. Semin. Hematol. 45, 210-217 (2008).

29. Artz, A. S. et al. Prevalence of anemia in skilled-nursing home residents. Arch. Gerontol. Geriatr. 39, 201-206 (2004).

30. Prakash, D. Anemia in the ICU. Crit. Care Clin. 28, 333-343 (2012).

31. Weiss, G., Ganz, T. \& Goodnough, L. T. Anemia of inflammation. Blood 133, 40-50 (2019).

32. Ganz, T. Anemia of Inflammation. N. Engl. J. Med. 381, 1148-1157 (2019).

33. Anía, B. J., Suman, V. J., Fairbanks, V. F., Rademacher, D. M.Ill., \& Melton, L. J. Incidence of anemia in older people: an epidemiologic study in a well defined population. J. Am. Geriatr. Soc. 45, 825-831 (1997).

34. Mugisha, J. O., Baisley, K., Asiki, G., Seeley, J. \& Kuper, H. Prevalence, types, risk factors and clinical correlates of anaemia in older people in a rural ugandan population. PLOS ONE 8, e78394 (2013).

35. Semba, R. D. et al. Types of anemia and mortality among older disabled women living in the community: the Women's Health and Aging Study I. Aging Clin. Exp. Res. 19, 259-264 (2007)

36. Zwart, S. R., Pierson, D., Mehta, S., Gonda, S. \& Smith, S. M. Capacity of omega-3 fatty acids or eicosapentaenoic acid to counteract weightlessness-induced bone loss by inhibiting NF-kappaB activation: from cells to bed rest to astronauts. J. Bone Miner. Res. 25, 1049-1057 (2010).

37. Smith, G. I. et al. Dietary omega-3 fatty acid supplementation increases the rate of muscle protein synthesis in older adults: a randomized controlled trial. Am. J. Clin. Nutr. 93, 402-412 (2011).

38. Momken, I. et al. Resveratrol prevents the wasting disorders of mechanical unloading by acting as a physical exercise mimetic in the rat. FASEB J. 25, 3646-3660 (2011).

39. Sjöstrand, T. The formation of carbon monoxide by the decomposition of haemoglobin in vivo. Acta Physiol. Scand. 26, 338-344 (1952).

40. Coburn, R. F. The measurement of endogenous carbon monoxide production. J. Appl. Physiol. 112, 1949-1955 (2012).

41. Kotal, P. \& Fevery, J. Quantitation of urobilinogen in feces, urine, bile and serum by direct spectrophotometry of zinc complex. Clin. Chim. Acta 202, 1-9 (1991).

42. Bloomer, J. R., Berk, P. D., Howe, R. B. \& Berlin, N. I. Interpretation of plasma on studies with radiobilirubin. JAMA J. Am. Med. Assoc. 218, 216 (1971).

43. Shi, H., Bencze, K. Z., Stemmler, T. L. \& Philpott, C. C. A Cytosolic iron chaperone that delivers iron to ferritin. Science 320, 1207-1210 (2008).

44. Levitt, D. G. \& Levitt, M. D. Carbon monoxide: a critical quantitative analysis and review of the extent and limitations of its second messenger function. Clin. Pharmacol. 7, 37-56 (2015).

45. World Health Organization. Haemoglobin concentrations for the diagnosis of anaemia and assessment of severity. 1-6 (WHO, 2011).

46. De Santo, N. G. et al. Anemia and Erythropoietin in Space Flights. Semin. Nephrol. 25, 379-387 (2005).

47. Alfrey, C. P., Rice, L., Udden, M. M. \& Driscoll, T. B. Neocytolysis: physiological down-regulator of red-cell mass. Lancet 349, 1389-1390 (1997).

48. Rice, L. \& Alfrey, C. The negative regulation of red cell mass by neocytolysis: physiologic and pathophysiologic manifestations. Cell. Physiol. Biochem. 15, 245-250 (2005).

49. Socolovsky, M. Exploring the erythroblastic island. Nat. Med. 19, 399-401 (2013).

50. Kristiansen, M. et al. Identification of the haemoglobin scavenger receptor. Nature 409, 198-201 (2001)

51. Schaer, D. J., Vinchi, F., Ingoglia, G., Tolosano, E. \& Buehler, P. W. Haptoglobin, hemopexin, and related defense pathways-basic science, clinical perspectives, and drug development. Front. Physiol. 5, 415 (2014).

52. Shih, A. W. Y., McFarlane, A. \& Verhovsek, M. Haptoglobin testing in hemolysis: measurement and interpretation. Am. J. Hematol. 89, 443-447 (2014).

53. Kunisaki, Y. et al. Arteriolar niches maintain haematopoietic stem cell quiescence. Nature 502, 637-643 (2013).

54. Adler, B. J., Kaushansky, K. \& Rubin, C. T. Obesity-driven disruption of haematopoiesis and the bone marrow niche. Nat. Rev. Endocrinol. 10, 737-748 (2014).

55. Pinho, S. \& Frenette, P. S. Haematopoietic stem cell activity and interactions with the niche. Nat. Rev. Mol. Cell Biol. 20, 303-320 (2019).
56. Dimeo, F., Knauf, W., Geilhaupt, D. \& Böning, D. Endurance exercise and the production of growth hormone and haematopoietic factors in patients with anaemia. Br. J. Sports Med. 38, e37 (2004).

57. Moretti, D. et al. An intensified training schedule in recreational male runners is associated with increases in erythropoiesis and inflammation and a net reduction in plasma hepcidin. Am. J. Clin. Nutr. 108, 1324-1333 (2018).

58. Payne, M. W. C., Uhthoff, H. K. \& Trudel, G. Anemia of immobility: Caused by adipocyte accumulation in bone marrow. Med. Hypotheses 69, 778-786 (2007).

59. Turner, R. T., Martin, S. A. \& Iwaniec, U. T. Metabolic coupling between bone marrow adipose tissue and hematopoiesis. Curr. Osteoporos. Rep. 16, 95-104 (2018).

60. Zhang, Z. et al. Bone marrow adipose tissue-derived stem cell factor mediates metabolic regulation of hematopoiesis. Haematologica 104, 1731-1743 (2019).

61. Suresh, S., de Castro, L. F., Dey, S., Robey, P. G. \& Noguchi, C. T. Erythropoietin modulates bone marrow stromal cell differentiation. Bone Res. 7, 21 (2019).

62. Robles, $\mathrm{H}$. et al. Characterization of the bone marrow adipocyte niche with threedimensional electron microscopy. Bone 118, 89-98 (2019).

63. Yokoyama, T., Etoh, T., Kitagawa, H., Tsukahara, S. \& Kannan, Y. Migration of erythroblastic islands toward the sinusoid as erythroid maturation proceeds in rat bone marrow. J. Vet. Med. Sci. 65, 449-452 (2003).

64. Kaasik, K. \& Chi Lee, C. Reciprocal regulation of haem biosynthesis and the circadian clock in mammals. Nature 430, 467-471 (2004).

65. Yin, L. et al. Rev-erb, a heme sensor that coordinates metabolic and circadian pathways. Science (80-) 318, 1786-1789 (2007).

66. Freeman, S. L. et al. Heme binding to human CLOCK affects interactions with the E-box. Proc. Natl Acad. Sci. U.S.A. 116, 19911-19916 (2019).

67. Dioum, E. M. et al. NPAS2: a gas-responsive transcription factor. Science (80-.) 298, 2385-2387 (2002).

68. Gachon, F., Olela, F. F., Schaad, O., Descombes, P. \& Schibler, U. The circadian PARdomain basic leucine zipper transcription factors DBP, TEF, and HLF modulate basal and inducible xenobiotic detoxification. Cell Metab. 4, 25-36 (2006).

69. Panda, S. Circadian physiology of metabolism. Science 354, 1008-1015 (2016).

70. Klemz, R. et al. Reciprocal regulation of carbon monoxide metabolism and the circadian clock. Nat. Struct. Mol. Biol. 24, 15-22 (2017).

71. Vincent, J. L. et al. Anemia and blood transfusion in critically III patients. JAMA 288, 1499 (2002).

72. New, P. W., Rawicki, H. B. \& Bailey, M. J. Nontraumatic spinal cord injury rehabilitation: pressure ulcer patterns, prediction, and impact. Arch. Phys. Med. Rehabil. 85, 87-93 (2004).

73. Chan, T. \& Ganasekaran, G. The effect of anemia on the functional outcomes of the stroke patients and the efficiency of their stroke rehabilitation. J. Stroke Cerebrovasc. Dis. 24, 1438-1442 (2015).

74. Halawi, R., Moukhadder, H. \& Taher, A. Anemia in the elderly: a consequence of aging? Expert Rev. Hematol. 10, 327-335 (2017).

75. Mitlyng, B. L., Singh, J. A., Furne, J. K., Ruddy, J. \& Levitt, M. D. Use of breath carbon monoxide measurements to assess erythrocyte survival in subjects with chronic diseases. Am. J. Hematol. 81, 432-438 (2006).

76. Lestar, M., Gunnarsson, L., Lagerstrand, L., Wiklund, P. \& Odeberg-Wernerman, S. Hemodynamic perturbations during robot-assisted laparoscopic radical prostatectomy in $45^{\circ}$ Trendelenburg position. Anesth. Analg. 113, 1069-1075 (2011).

77. Berney, S., Denehy, L. \& Pretto, J. Head-down tilt and manual hyperinflation enhance sputum clearance in patients who are intubated and ventilated. Aust. J. Physiother. 50, 9-14 (2004).

78. Choi, Y. S. et al. Effects of head-down tilt on intrapulmonary shunt fraction and oxygenation during one-lung ventilation in the lateral decubitus position. $J$. Thorac. Cardiovasc. Surg. 134, 613-618 (2007).

79. Hirose, M., Hashimoto, S. \& Tanaka, Y. Effect of the head-down tilt position during lower abdominal surgery on endocrine and renal function response. Anesth. Analg. 76, 40-44 (1993).

80. Hayden, S. J., Albert, T. J., Watkins, T. R. \& Swenson, E. R. Anemia in critical illness. Am. J. Respir. Crit. Care Med 185, 1049-1057 (2012).

81. Brusotti, G. et al. Betulinic acid is a PPARy antagonist that improves glucose uptake, promotes osteogenesis and inhibits adipogenesis. Sci. Rep. 7, 5777 (2017).

82. Strewe, C. et al. PlanHab study: consequences of combined normobaric hypoxia and bed rest on adenosine kinetics. Sci. Rep. 8, 1-9 (2018).

83. Shahin, N., Louati, H. \& Trudel, G. Measuring human hemolysis clinically and in extreme environments using endogenous carbon monoxide elimination. Ann. Biomed. Eng. 48, 1540-1550 (2020).

84. Peak Laboratories. Peak Performer 1 RCP (910-Series) User Manual (Peak Laboratories, 2008).

85. Burge, C. M. \& Skinner, S. L. Determination of hemoglobin mass and blood volume with CO: evaluation and application of a method. J. Appl. Physiol. 79, 623-631 (1995).

86. Zavorsky, G. S. et al. Rates of carbon monoxide elimination in males and females. Physiol. Rep. 2, 1-10 (2014). 
87. Levasseur, L., Galliot-Guilley, M., Richter, F., Scherrmann, J. M. \& Baud, F. J. Effects of mode of inhalation of carbon monoxide and of normobaric oxygen administration on carbon monoxide elimination from the blood. Hum. Exp. Toxicol. 15, 898-903 (1996)

88. Bruce, M. C. \& Bruce, E. N. Analysis of factors that influence rates of carbon monoxide uptake, distribution, and washout from blood and extravascular tissues using a multicompartment model. J. Appl. Physiol. 100, 1171-1180 (2006).

89. Garvican, L. A. et al. Carbon monoxide uptake kinetics of arterial, venous and capillary blood during CO rebreathing. Exp. Physiol. 95, 1156-1166 (2010).

\section{ACKNOWLEDGEMENTS}

We would like to thank the volunteers for their participation, the staff at the Medes Institute for Space Medicine and Physiology especially Marie-Pierre Bareille, Arnaud Beck, Marie-Claude Costes-Salon, Patrick Person, and Corinne Lombard for support during the study, Doug Worthy and Michele Rauh from the Canadian Green House Gases program, Theresa Backlund, Téa Backlund, Nibras Shahin, and Justin Thomas for their assistance with the $\mathrm{CO}$ and urobilinoids measures, Carolynn Cook for the graphs and Dr. Hans Uhthoff with the critical review of the manuscript. The bed rest study was funded by the European Space Agency, the Center National d'Etudes Spatiales and the Canadian Space Agency (CSA). Investigators costs were covered under CSA grant 15EXPBEDST. The European Space Agency established the study design, dates, sample size, and duration of the bed rest study. Funders had no role in the conduct of the study; collection, management, analysis, and interpretation of the data; preparation, review, or approval of the manuscript; and decision to submit the manuscript for publication.

\section{AUTHOR CONTRIBUTIONS}

Concept and design: G.T. Acquisition, analysis, or interpretation of data: G.T., K.C., O.L., H.L., T.R. Drafting of the manuscript: G.T., K.C. Critical revision of the manuscript for important intellectual content: All authors. Statistical analysis: K.C., T.R., G.T. Obtained funding: G.T., O.L.

\section{COMPETING INTERESTS}

The authors declare the following competing interests: Dr. G.T. has received funding from the Canadian Space Agency to conduct this and other experiments. No other competing interests were reported by the other authors.

\section{ADDITIONAL INFORMATION}

Supplementary information The online version contains supplementary material available at https://doi.org/10.1038/s41526-021-00132-0.

Correspondence and requests for materials should be addressed to G.T.

Reprints and permission information is available at http://www.nature.com/ reprints

Publisher's note Springer Nature remains neutral with regard to jurisdictional claims in published maps and institutional affiliations.

(i) Open Access This article is licensed under a Creative Commons Attribution 4.0 International License, which permits use, sharing, adaptation, distribution and reproduction in any medium or format, as long as you give appropriate credit to the original author(s) and the source, provide a link to the Creative Commons license, and indicate if changes were made. The images or other third party material in this article are included in the article's Creative Commons license, unless indicated otherwise in a credit line to the material. If material is not included in the article's Creative Commons license and your intended use is not permitted by statutory regulation or exceeds the permitted use, you will need to obtain permission directly from the copyright holder. To view a copy of this license, visit http://creativecommons. org/licenses/by/4.0/.

(c) The Author(s) 2021 